\title{
Clayton Mendonça Cunha Filho. Formação do Estado e Horizonte Plurinacional na Bolívia. 373
}

\author{
páginas. Curitiba, Editorial Appris, 2018.
}

Neste século, a compreensão dos processos sociopolíticos e culturais que marcam a política boliviana foram objeto de diferentes reflexões e obras que fizeram aumentar o número de especialistas considerados bolivianistas fora daquele país. Muitas destas análises não podem ser consideradas, na verdade, uma grande novidade, dessa forma, nem todos(as) que se dedicaram ao tema podem ser tidos como especialistas, como é o caso de Clayton Mendonça Cunha Filho, um pesquisador brasileiro, autor da obra que é analisada nesta oportunidade.

O livro em questão é resultante da sua tese de doutorado, uma oportunidade de realização de um estudo aprofundado das experiências que marcam a Bolívia contemporânea, experiências estas que lançam desafios para as ciências sociais em sua busca de compreensão dos fatos e processos fundamentais que promoveram mudanças profundas no país andino.

Ao tratar do processo de formação, a análise apresentada pelo autor já demonstra não se tratar de algo consolidado em termos estruturais. Dessa forma, quando se fala do aspecto plurinacional do Estado boliviano, essa plurinacionalidade é algo que foi colocado adiante, para ser alcançada, no horizonte, não se deu por completo. Assim percebemos aquilo que existe de concreto e o que existe como algo idealizado, bem como as limitações existentes nas mudanças realizadas e nas mudanças em curso. Estruturas antigas ainda persistem e convivem com as inovações.

Este estudo contribui de modo muito significativo ao permitir o reconhecimento de cada questão de acordo com o seu peso, sua medida, bem como as influências, os caminhos tomados em todo o processo histórico de formação do Estado boliviano até o período de mudanças mais recentes. 0 projeto plurinacional se originou de mudanças promovidas a partir da ascensão de Evo Morales à presidência do país. Ao lado disso, o projeto surgiu em um contexto de crise, lutas e pressões contra o modelo neoliberal. Entretanto, sua 
emergência não deve ser atribuída apenas a este momento em que as bandeiras estavam convulsionadas, mas sim como expressão multicolorida de diferentes matrizes que confluíram, ao longo da história e da história recente até se chegar a este novo projeto formulado.

O próprio autor adverte sobre as combinações diferentes e possíveis quanto às tradições, os jogos de força e de interesses, as clivagens mesmo que, por fim, ajudaram a escrever a história boliviana desde sua experiência colonial, e ainda de modo mais específico, os processos mais decisivos de sua história contemporânea a partir do século XX. De uma maneira geral, temos que observar que o elemento a ser combatido pelo projeto plurinacional foi a tradição liberal pelo seu conteúdo oligárquico, de um Estado marcado como excludente e racista, historicamente.

É a partir deste ponto que a tese central do autor ganhe força. Aqui, Cunha Filho expõe conceitos centrais, termos e relações que valorizam a necessidade de compreensão das distintas matrizes. Não se refere necessariamente aos projetos políticos de construção nacional, mas matrizes mesmo, sem uma ideia de intencionalidade e racionalidade por parte das bolivianas elites. Temos, assim, elementos que, ao longo da historia recente do país, sejam importantes a reconhecer como determinantes da mudança recente e, ao mesmo tempo, também como parte deste movimento em curso.

Tomando em consideração a historiadora Brooke Larson, o pesquisador chama atenção para a ideia de que exista uma linguagem do conflito que gera alguns padrões de interação e relações entre o Estado e os atores sociais reativos em termos dos seus projetos em curso. Seriam estes padrões, discursivo-legais que levariam a uma necessidade de adaptação, mutação e mudança para conformar uma base de legitimidade política. A ideia central também é a de designar com precisão a cada uma das matrizes diferentes a um determinado momento, uma etapa ou mesmo uma era. Seguramente, existem momentos de exercício hegemônico do poder, mas as contradições mesmas, ou um simples modus operandi de sistemas políticos e econômicas de países com herança colonial e dependente do capitalismo, já seriam uma forma bem significativa que abarca múltiplas experiências vividas pelo país. Isto nos leva ao entendimento do grau de desenvolvimento e inserção mundial, ao mesmo tempo que nos coloca diante de aspectos pré-capitalistas e comunidades isoladas, como o caso da América Latina e da Bolívia, em especial. Referindose a René Zavaleta, Cunha Filo nos alerta para uma chave interpretativa costumeira quando se trata do caso boliviano em termos da sociedade abigarrada, no sentido de descontinuação e desconexão. Trata-se de um 
Estado não formado de um modo linear em relação à expansão da sua soberania, muito pelo contrário, temos uma experiência lenta e negociada até chegar a estabelecer seus limites e fronteiras nacionais. Recordando a George Gray Molina, teríamos protoestados diversos, uma dinâmica dialógica entre Estado e Sociedade em suas negociações por legitimidades sucessivas. Por um lado, isto impediu a violência fragmentadora, ao mesmo tempo em que impediu a constituição de um núcleo de legitimidade unificado.

O livro dá conta desses processos desconexos, sobrepostos, conflitivos e nada lineares que nos levam à Bolívia contemporânea. Para isso, o mesmo se organiza em três capítulos que discutem cada uma das diferentes matrizes identificadas, sendo depois seguido por um capítulo derradeiro em que é tratada a situação de um horizonte plurinacional, estabelecido como um ideário para o cenário boliviano. Desta forma, vamos seguindo a leitura considerando as questões principais, aspectos e chaves explicativas para estas diferentes matrizes, até o ponto de chegarmos à consideração de como elas confluem, impactam ou são superadas pelo horizonte da plurinacionalidade.

O capítulo segundo trata da matriz do indianismo comunitário. O cientista político prefere esta terminologia ao considerar a vertente mais contemporânea e o objeto de estudos sobre o indianismo boliviano desde os anos 1960. Entretanto, nosso autor reconheça que a origem destas influências é muito mais profunda na história do país. Além de que estes marcaram os processos de colonização além de revoltas e mobilizações indígenas de séculos precedentes. A defesa da autonomia das terras comunais sempre foi um ponto fundamental para se compreender esta matriz política, não exclusivamente por ser uma bandeira, mas por ter sido algo conformado na constituição mesmo do país que manteve um regime dual por debilidades do Estado ao exercer seu controle. Para o autor, as práticas protoestatais formaram esta matriz, principalmente a partir de conflitos postos entre as últimas décadas do século XIX e o pós-Segunda Guerra Mundial. Isto no sentido de colocar no horizonte político algo como a possibilidade de autogoverno e gestão por parte dos povos originários. Mas, o autor também reconhece que a própria conformação do indigenismo recente, o que compõe o projeto plurinacional, é fruto das bandeiras de representação política indígena no sistema político do país, a partir da década de 1990. Percebe-se que não há um movimento unificado, por isto o livro segue dando a devida atenção às clivagens existentes. $\mathrm{O}$ indianismo é um elemento constante e que pode surgir em diferentes matrizes. Isto também dificulta a ideia de um partido único para defender a causa indígena, pois além das dicotomias rural/urbano, devem ser 
consideradas as grandes diferenças regionais entre o altiplano e o leste, por exemplo. O Partido Movimiento al Socialismo (MAS) conseguiu ser o possível canal político para a agenda indígena porque foi fortalecido pelo movimento coca Chapare em um contexto de defesa da agenda coca a partir dos anos 1990.

Além do período mais recente, o autor também faz uma discussão ampla da história política do país, desde os movimentos indígenas do século 18 às repercussões da Revolução Nacional de 1952 para essa matriz indianista. É fundamental, em sua análise do indianismo boliviano, a avaliação do movimento katarista como elemento finalizador de uma visão nacional ou possibilidade tanto para a agenda indígena quanto para o resgate do sistema dual do passado colonial. Isso, no período mais recente, se soma a um horizonte plurinacional como elemento para permitir o avanço de uma agenda, mas a partir do reconhecimento das características de uma sociedade multiétnica e marcada pela multiculturalidade, ou seja, da necessidade de reconhecer suas diferenças internas e sinalizar um Estado de múltiplas nações.

A terceira matriz é a nacional-popular, bandeira central de partidos, lideranças e movimentos que, ao longo dos dois séculos anteriores, apontou a importância do público e do Estado, bem como a própria dimensão da cidadania democrática buscando um regime de inclusão. Como explica o autor, neste projeto não existe exclusividade boliviana, uma vez que esses movimentos e ideais estivessem presentes e fortes em outras experiências por toda a região. Para alguns, essas foram as chamadas experiências populistas ou desenvolvimentistas. No que diz respeito ao complexo e polêmico termo de populismo, temos uma alusão aos estudos de Ernesto Laclau que muito bem destaca o populismo como forma de fazer política ao invés de destacar uma base política e ideológica definida na sociedade. A partir daí, o autor apresenta uma análise da história boliviana após sua independência para identificar os atores políticos que representam a origem desta matriz, neste caso, aludindo ao papel de Manuel Isidoro Belzu (1848-1855) e de seu governo para o início de uma política de massa no país. A seguir, tivemos a experiência de Andrés Ibáñez em 1876-1877; depois o socialismo militar pós-Guerra do Chaco contra o Paraguai, na década de 1930, para finalmente atingir o ápice do projeto com a Revolução de 52.

O trabalho realizado pelo autor é extremamente detalhado quanto aos acontecimentos históricos e períodos importantes na vida política da Bolívia, e seria até impossível considerar todos esses detalhes. Diante disso, nos centramos nos processos considerados cruciais, como o fato de que foi a partir 
da chegada de Victor Paz Estensoro do MNR ao poder (1952) que a matriz nacional-popular mudou a cara do país, constituindo um regime político de massas com a introdução do sufrágio universal, por exemplo. Os aspectos centrais do projeto do MNR no poder, assim como a nacionalização do setor de mineração e a reforma agrária são outros elementos bem explorados pelo cientista político em seu livro. Resta somente identificar algumas conclusões e argumentos importantes do ponto de vista do autor para compreender os efeitos da revolução popular boliviana. Assim, é possível destacar a compreensão sobre um processo centrífugo, reconhecido em sua capacidade estatal limitada e na necessidade de atuação de atores locais ou vinculados a setores importantes, como caudilhos ou sindicatos. Embora tenha causado um golpe decisivo aos antigos atores vinculados ao meio rural com o fim do sistema de hacienda, tivemos um sistema ainda protoestatal vinculado a outros atores, seja das áreas urbanas ou de setores emergentes.

Pode-se apontar também o papel do próprio partido do governo, o MNR, e seus vínculos clientelistas estabelecidos, principalmente com os sindicatos, por meio das figuras de chefes políticos. Uma das tentativas de resgate da soberania do Estado remonta à política de reestruturação das Forças Armadas. O projeto político do MNR deu certo, mas fortaleceu as contradições históricas e políticas e gerou uma série de conflitos políticos que fizeram crescer as forças da oposição.

A análise proposta pelo autor é extremamente relevante para olhar as contradições mais profundas na Bolívia, como o paradoxo da revolução a partir das contrarreformas de 1956 e até o surgimento de um novo extrato senhorial responsável pelo abandono do nacional-popular para restabelecer uma ordem oligárquica liberal. Nos anos 1960, e, principalmente, nos anos 1970, o cenário era muito diferente daquele que marcou a revolução. A Bolívia viveu a experiência de um golpe militar em 1964 e a relação entre o Estado e os trabalhadores tornou-se mais hostil, até pelo surgimento de movimentos de guerrilha e o assassinato de Ernesto Che Guevara, em 1967. Assim, tínhamos um projeto revolucionário nacional, que surgiu depois da Guerra do Chaco, mas que agora se anunciava como uma luta pelos negócios inacabados da revolução de 1952. É também possível perceber dessa obra do autor, uma espécie de movimento pendular do MNR que depois da revolução se orientou mais para o sentido revolucionário, mas em um segundo momento fez o movimento para a matriz nacional, principalmente, após 1956. Quanto à ditadura militar, especialmente o período de Hugo Banzer (1971-1978), foi essencial para uma mudança significativa com a abertura econômica ao capital estrangeiro e a 
repressão aos partidos e sindicatos de esquerda. Na década de 1980, tivemos a marcada instabilidade do processo de transição para a democracia, um pacto com a democracia e o avanço do neoliberalismo. Mas o período mais conturbado da vida política boliviana contemporânea, ocorreu entre os anos 1990 e 2000, período que marcaria também a realização de protestos populares e o surgimento dos novos movimentos sociais. A intensa mobilização e crise em torno da crise da água (2000) e da crise do gás (2003) foi decisiva para sinalizar o início de uma agenda política alternativa para o país, como destaca o autor. Assim, a partir de 2005, evidencia-se um projeto contra hegemônico na Bolívia, marcado pelo surgimento de atores como Evo Morales e o partido, MAS, após a crise que levou à renúncia de Sánchez de Lozada (2003).

Com a eleição de Evo Morales pelo MAS, em 2005 mais do que um resgate da matriz nacional-popular, havia um novo projeto político proposto como horizonte, o plurinacional. Nesse sentido, é possível perceber, segundo Clayton Cunha Filho, uma grande complexidade da sociedade boliviana a partir do surgimento de novos grupos questionadores da sociedade política nacional excludente, a favor do reforço da autonomia dos trabalhadores e indígenas contra o Estado e a legitimidade do autogoverno.

Para o autor, seria possível considerar para o caso boliviano que a partir de suas três matrizes entendemos a conexão institucional como parte do processo constituinte de 2006 que levou adiante uma demanda de redefinição e aprofundamento da própria democracia. Obviamente, a questão indígenacomunitária foi considerada pelo amplo debate sobre a diversidade e a pluralidade da sociedade boliviana que levou a uma definição de sua plurinacionalidade. O debate, a revisão da literatura e os argumentos apresentados no trabalho são densos demais para serem abordados em uma revisão como esta. Assim, é importante destacar os pontos centrais da análise sobre o caso boliviano, como, por exemplo, o fato de que, a partir de 2006, tínhamos uma perspectiva indígena e comunitária, mas também compartilhando espaço na esfera jurídico-constitucional. Com a matriz liberal, uma vez que as rupturas não sejam decisivas ou completas, a democracia representativa e o Estado de Direito continuam como elementos fundamentais da política boliviana. Os elementos simbólicos adotados são fundamentais para o reconhecimento dos povos indígenas, de sua cultura e de seus direitos à autodeterminação. Assim constituímos outras possibilidades de compreensão e realização da cidadania a partir de uma visão comunitária e não meramente individualmente como preconizada pela matriz liberal. Da mesma forma, é 
importante perceber como este trabalho nos permite compreender como elementos além daqueles que compõem as reivindicações relacionadas à classe social, sobretudo ao étnico-racial, ganham centralidade, até por ser a base fundamental para a compreensão da herança colonial do projeto modernizador europeu. $\mathrm{O}$ projeto plurinacional resgata a matriz indígena, mas com avanços, na medida em que destaca elementos do nacional-popular para se contrapor ao projeto neoliberal hegemônico, ao fazer combinações institucionais de seu componente comunitário de autogestão com o arcabouço jurídico do Estado Liberal de Lei, de certa forma, a matriz liberal.

O livro se torna uma oportunidade para uma compreensão apurada dos encontros e desencontros, da dinâmica particular de cada uma das diferentes matrizes que compõem a vida política boliviana, de como estas foram superadas, de alguma forma, a partir do projeto político implementado pelo governo de Evo Morales do MAS e como, não necessariamente, supera estes e outros projetos, mas sim avança e faz combinações necessárias, reconhecendo, na prática, seus limites e definindo um horizonte para este projeto politico.

Renata Peixoto de Oliveira Universidade Federal da Integração Latino-Americana (UNILA)

\section{$(c)$ EY}

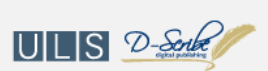

New articles in this journal are licensed under a Creative Commons Attribution 4.0 United States License.

This journal is published by the University Library System of the University of Pittsburgh as part of its D-Scribe Digital Publishing $\underline{\text { Program, and is cosponsored by the University of Pittsburgh Press. }}$ 